\title{
Impact of Double Volume Exchange Transfusion on Biochemical Parameters in Neonatal Hyperbilirubinemia
}

\author{
Mohd Ibrahim Wani ${ }^{1}$, Mudasir Nazir ${ }^{*}$, Roumissa Lone ${ }^{2}$, Mohd Rafiq ${ }^{1}$, Syed Wajid Ali ${ }^{1}$ and Bashir \\ Ahmad Charoo ${ }^{1}$ \\ ${ }^{1}$ Department of Pediatrics and Neonatology, Sher-I-Kashmir Institute of Medical Sciences Hospital, India \\ ${ }^{2}$ Department of Community Medicine, Government Medical College Hospital, India

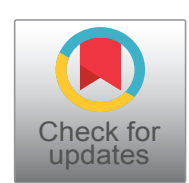

*Corresponding author: Mudasir Nazir, MD, Department of Pediatrics and Neonatology, Sher-I-Kashmir Institute of Medical Sciences Hospital, Soura, Srinagar, India, 190011, Tel: 0194-2400419

\begin{abstract}
Background: Almost $60 \%$ of normal healthy term babies and $80 \%$ of preterm babies develop visible jaundice in the first week of life. Although the outcome of the majority is benign, newborns with untreated severe hyperbilirubinemia can develop short and long-term sequelae of bilirubin encephalopathy.
\end{abstract}

Objectives: This study was designed to evaluate the impact of exchange transfusion on various biochemical parameters and to assess the need for routine calcium gluconate supplementation during the procedure.

Methodology: We studied 84 newborn double volume exchange transfusions and recorded various biochemical parameters of sodium, potassium, calcium, ph and blood sugar during the procedure. Mostly fresh donor blood was employed for the procedures. Nearly $74 \%$ transfusions were performed with donor blood aged less than 2 days.

Results: We observed no clinically significant alteration in recorded biochemical parameters during and after exchange transfusion. Routine intravenous calcium gluconate was not given to patients during the procedure. Though we observed a fall in serum calcium level during transfusion, but the concentrations remained within normal physiological range. Insignificant variation in recorded parameters and zero mortality were attributed to mostly using fresh blood for the exchange transfusions.

Conclusion: We concluded that there was no significant alteration in serum electrolytes during and after exchange transfusion. Further, in contrast to the earlier reports of higher incidence of hyperkalemia during exchange transfusion, we observed a paradoxical fall in serum potassium during and after transfusion, although within normal range.

\section{Keywords}

Neonatal hyperbilirubinemia, Exchange transfusion, Biochemical parameters, Calcium gluconate, CPDA blood

\section{Introduction}

Jaundice is one of the most common clinical problems in neonatal medicine [1]. Almost $60 \%$ of normal healthy term babies and $80 \%$ of preterm babies develop visible jaundice in the first week of life [1]. A significant proportion of these neonates develop pathological hyperbilirubinemia, which is defined as hyperbilirubinemia that requires treatment during first week of life [1,2]. Neonatal jaundice is considered as one of the most common causes of readmission after early discharge from post-natal ward [3]. Premature babies have much higher incidence of neonatal jaundice requiring therapeutic intervention, than term newborns [4]. Although the outcome of the majority is benign, newborns with severe hyperbilirubinemia can develop acute bilirubin encephalopathy which could lead to higher mortality or kenicterus spectrum disorders, later on in life $[5,6]$. In order to prevent bilirubin induced neurologic dysfunction in acute hyperbilirubinemia, especially due to $\mathrm{Rh}$ or ABO incompatibility or G6PD deficiency where rate of bilirubin rise is very high, the exchange blood transfusion (EBT) is indicated to rapidly decrease the free bilirubin and the antibody load [6]. Although it is considered to be a safe undertaking, but changes may take place in various serum biochemical parameters, plasma

Citation: Wani MI, Nazir M, Lone R, Rafiq M, Ali SW, et al. (2018) Impact of Double Volume Exchange Transfusion on Biochemical Parameters in Neonatal Hyperbilirubinemia. Int J Pediatr Res 4:038. doi. org/10.23937/2469-5769/1510038

Accepted: October 03, 2018: Published: October 05, 2018

Copyright: (C) 2018 Wani MI, et al. This is an open-access article distributed under the terms of the Creative Commons Attribution License, which permits unrestricted use, distribution, and reproduction in any medium, provided the original author and source are credited. 
osmolality and electrolyte profile in the infant's blood, which may be significant at times, giving rise to various complications including hyponatremia, hypoglycemia, and hyperkalemia, after the exchange [7-10].

This prospective study was conducted to evaluate the impact of fresh CPDA-1 anticoagulated blood on various biochemical parameters during exchange transfusion and to assess routine use of intravenous calcium gluconate for prevention of hypocalcemia during the procedure.

\section{Material and Methods}

The study was conducted in the Neonatal intensive care unit, Department of Pediatrics and Neonatology, Sher-Kashmir Institute of Medical Sciences Srinagar Kashmir. The department has its own laboratory facility for biochemical analysis with semi-automatic Gem 3000 analyzer for Blood gases, electrolytes, lactate, bicarbonate and ionized calcium. The study was conducted over a period of two years from January 2014 to December 2015. The indications for exchange transfusion were different for preterm and term babies. Based on our current protocol, critical values for exchange transfusion in preterms include: Infants $<1 \mathrm{~kg}$ at 10 to $12 \mathrm{mg} / \mathrm{dl}$, infants $1-1.5 \mathrm{~kg}$ at $12-15 \mathrm{mg} / \mathrm{dl}$, infants $1.5-2 \mathrm{~kg}$ at $15-$ $18 \mathrm{mg} / \mathrm{dl}$ and infants $2-2.5 \mathrm{~kg}$ at $18-20 \mathrm{mg} / \mathrm{dl}$ [11]. Indications for exchange transfusion in term infants were based on the consensus guidelines of American academy of pediatrics Subcommittee [12] (Figure 1). We excluded babies with shock, renal failure and those with underlying biochemical and electrolyte abnormalities.

All EBTs were performed under standard aseptic conditions via umbilical catheterization or via peripheral route using radial artery (for removing blood) and a peripheral vein (for fresh blood infusion). Blood exchange was done in aliquots of $5 \mathrm{ml}$ for $<1.5 \mathrm{~kg}, 10 \mathrm{ml}$ for $1.5-2.5 \mathrm{~kg}, 15 \mathrm{ml}$ for $2.5-3.5 \mathrm{~kg}$ and $20 \mathrm{ml}>3.5 \mathrm{~kg}$ babies. The amount of blood exchanged was double the infant's total circulating blood $(85 \mathrm{ml} / \mathrm{kg} \times 2)$. The selection of blood for transfusion was done depending upon the blood group of babies as well as mother and was selected as per the following criteria:

- Fresh $<7$ days old irradiated whole blood or reconstituted whole blood (hematocrit 40-50\%) made from packed RBCs and fresh frozen plasma collected in citrate phosphate dextrose.

- In Rh hemolytic disease, if blood was prepared be-

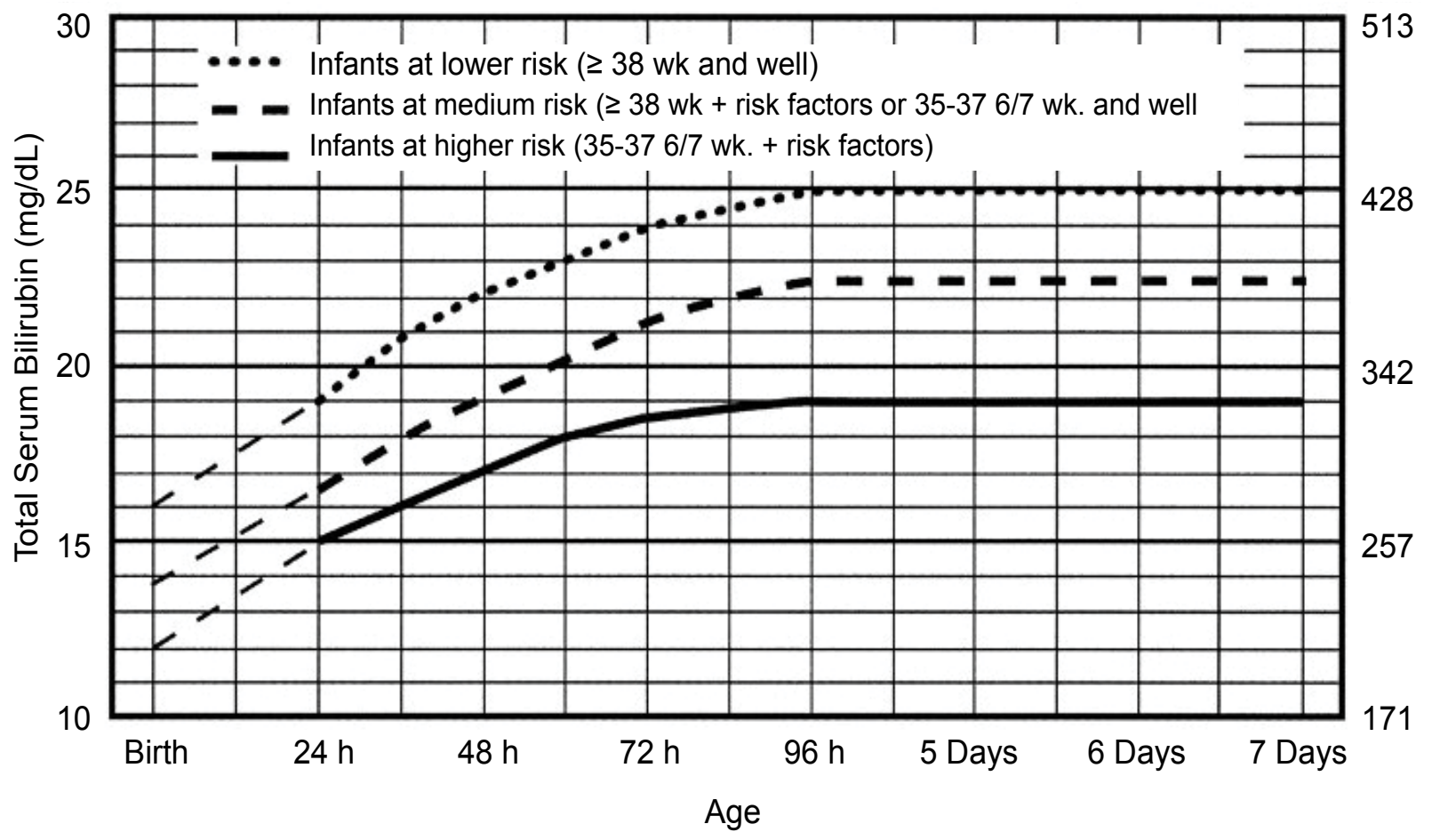

- The dashed lines for the first 24 hours indicate uncertainty due to a wide range of clinical circumstances and a range of responses to phototherapy.

- Immediate exchange transfusion is recommended if infant shows signs of acute bilirubin encephalopathy (hypertonia, arching, retrocollis, opisthotonos, fever, high pitched cry) or if TSB is $\geq 5 \mathrm{mg} / \mathrm{dL}$ ( $85 \mu \mathrm{mol} / \mathrm{L}$ ) above these lines.

- Risk factors- isoimmune hemolytic disease. G6PD deficiency, asphyxia, significate lethargy, temperature instability, sepsis, acidosis.

- Measure serum albumin and calculate B/A ratio (See legend).

- Use total bilirubin. Do not subtract direct reacting or conjugated bilirubin.

- If infant is well and 35-37 6/7 wk (median risk) can individualize TSB levels for exchange based on actual gestational age.

Figure 1: Guidelines for exchange transfusion in infants 35 or more weeks' gestation. 
fore delivery type $\mathrm{O}$ Rh negative cross matched against mother's blood was used.

- In ABO incompatibility the blood type O Rh negative or Rh compatible with the mother and infant was used. Usually type $O$ used with $A B$ plasma to ensure that no anti $A$ or anti $B$ antibodies were present.

- In non-immune hyperbilirubinemia blood typed and cross matched against the plasma and RBCs.

- Continuous monitoring of hemodynamic parameters (heart rate, respiratory rate, capillary refill time and blood pressure) was done during the procedure. Assessment of serum levels of sodium, potassium, calcium, $\mathrm{Ph}$ and glucose was done at different intervals i.e, before, during, immediately after exchange and at 12 hours post-exchange, using $1 \mathrm{ml}$ of peripheral blood for each analysis. Babies with shock and underlying biochemical and electrolyte abnormalities were excluded.

The study was approved by the institutional ethics

Table 1: Baseline patient characteristics.

\begin{tabular}{|c|c|c|}
\hline No. & Parameter & No (\%) \\
\hline \multirow[t]{3}{*}{1} & \multicolumn{2}{|l|}{ Sex } \\
\hline & Male & $25(59.5)$ \\
\hline & Female & $17(40.5)$ \\
\hline 2 & Age at the time of EBT, mean (range) & $3.2(1-8)$ \\
\hline \multirow[t]{3}{*}{3} & \multicolumn{2}{|c|}{ Gestation } \\
\hline & Term & $32(76.2)$ \\
\hline & Preterm & $10(23.8)$ \\
\hline \multirow[t]{6}{*}{4} & \multicolumn{2}{|l|}{ Birth order } \\
\hline & 1 & $16(38.1)$ \\
\hline & 2 & $11(26.2)$ \\
\hline & 3 & $11(26.2)$ \\
\hline & 4 & $3(7.1)$ \\
\hline & 5 & $1(2.4)$ \\
\hline \multirow[t]{4}{*}{5} & \multicolumn{2}{|l|}{ Diagnosis } \\
\hline & Rh incompatibility & $8(19)$ \\
\hline & ABO incompatibility & $20(47.6)$ \\
\hline & Unexplained & $14(33.3)$ \\
\hline \multirow[t]{3}{*}{6} & \multicolumn{2}{|l|}{ Comb's test } \\
\hline & Positive & $15(35.7)$ \\
\hline & Negative & 27 (64.3) \\
\hline
\end{tabular}

Table 2: Age of donor blood with mean serum potassium and ph.

\begin{tabular}{|l|l|l|l|}
\hline & $<\mathbf{2}$ days & $\mathbf{3 - 6}$ days & $>\mathbf{6}$ days \\
\hline No $(\%)$ & $62(73.8)$ & $12(14.3)$ & $10(11.9)$ \\
\hline Mean potassium level mEq/L & 3.4 & 6.26 & 11.2 \\
\hline Mean $\mathrm{pH}$ & 7.33 & & \\
\hline
\end{tabular}

committee and written informed consent were obtained from the parents/guardians of the patients.

\section{Statistical Analysis}

The observed data was entered in the computer to analyze with the help of MS, Excel and SPSS version 20 for windows. The values of biochemical parameters were presented as mean and SD and statistically significant difference was evaluated using one-way analysis of variance (ANOVA). Pre and post-exchange variables were compared using Chi square test. A p value of < 0.05 was considered as significant.

\section{Results}

Out of a total of 106 EBTs performed over the study period, 84 were included. Transfusions were performed via umbilical catheterization in 76(90.4\%) and via peripheral route in $8(9.6 \%)$ patients. Regarding the baseline characteristics-59.5\% were females and $40.5 \%$ were males, $76.2 \%$ and $23.8 \%$ were term and pre-term respectively. We observed that $19 \%$ patients had $\mathrm{Rh}$ incompatibility, $47.6 \%$ had $\mathrm{ABO}$ incompatibility and in $33.3 \%$ cases the cause of hyperbilirubinemia was unexplained. The direct coombs test was positive and negative in $35.7 \%$ and $64.3 \%$ patients respectively (Table 1). The mean age of the donor blood in our study was 2.24 days (Table 2 ). The mean serum glucose before, during and after exchange was $68.2 \pm 25.3 \mathrm{mg} /$ $\mathrm{dl}, 95.7 \pm 31.6 \mathrm{mg} / \mathrm{dl}$ and $101.5 \pm 40 \mathrm{mg} / \mathrm{dl}$ respectively. The rise in serum glucose during exchange was statistically significant $(p<0.05)$. However, serum glucose decreased to levels comparable to pre-exchange values at 12 hours after exchange ( $p>0.05)$. The mean blood ph before, during and after exchange was $7.40 \pm 0.04,7.41$ \pm 0.03 and $7.36 \pm 0.03$ respectively. Though the fall in ph during exchange was statistically significant, normal ph comparable to pre-exchange values got restored at 12 hours post exchange. There was no significant change in serum sodium during exchange transfusion. Mean serum potassium of patients before exchange was $4.29 \pm$ $0.70 \mathrm{mEq} / \mathrm{L}$, during exchange was $3.95 \pm 0.51 \mathrm{mEq} / \mathrm{L}$ and at completion of exchange was $3.93 \pm 0.63 \mathrm{mEq} / \mathrm{L}$. The decrease in potassium during exchange was statistically significant $(p<0.05)$. As compared to pre-exchange levels serum potassium was persistently low (3.69 \pm 0.38 $\mathrm{mEq} / \mathrm{L}$ ) even at 12 hours post exchange. We observed a significant fall in serum calcium of patients during exchange transfusion. Serum calcium decreased from a

Table 3: Patient serum parameters of calcium, sodium, potassium, glucose and ph.

\begin{tabular}{|l|l|l|l|l|}
\hline Parameter & Pre-exchange Mean \pm SD & Mid exchange mean \pm SD & $\begin{array}{l}\text { Immediate post exchange } \\
\text { mean } \pm \text { SD }\end{array}$ & P value (ANOVA) \\
\hline Calcium, mg/dl & $9.22 \pm 0.61$ & $8.80 \pm 0.83$ & $8.59 \pm 0.74$ & 0.01 \\
\hline Sodium, mEq/L & $145.57 \pm 7.811$ & $144 \pm 6.1$ & $144.3 \pm 4.2$ & 0.139 \\
\hline Potassium, mEq/L & $4.29 \pm 0.70$ & $3.95 \pm 0.51$ & $3.93 \pm 0.63$ & 0.011 \\
\hline Glucose, mg/dl & $68.2 \pm 25.3$ & $95.7 \pm 31.6$ & $101.5 \pm 40$ & 0.005 \\
\hline pH & $7.40 \pm 0.04$ & $7.41 \pm 0.03$ & $7.36 \pm 0.03$ & 0.021 \\
\hline
\end{tabular}


pre-exchange level of $9.22 \pm 0.61 \mathrm{mg} / \mathrm{dl}$ to a post-exchange level of $8.59 \pm 0.74 \mathrm{mg} / \mathrm{dl}$. The serum calcium values remained low $(8.34 \pm 0.59 \mathrm{mg} / \mathrm{dl})$ even at 12 hours after exchange (Table 3 ).

\section{Discussion}

In our study $\mathrm{ABO}$ incompatibility was the most common indication for exchange transfusion in neonatal jaundice (47.6\%). Sgro $M$, et al. and Chen, et al. also observed $A B O$ incompatibility to be the most common cause for exchange transfusion $[5,8]$. There was no death, nor any serious untoward event reported during any of the procedures. J Craig Jackson in their study observed that at least $2(2 \%)$ of the 106 patients died of complications probably attributable to exchange transfusion and both deaths were reported in very sick neonates [13]. Sick newborns and those with hemodynamic instability were excluded from our study. The mean pre-exchange transfusion serum sodium level observed was on higher side of normal range $(145 \pm 7.81 \mathrm{mEq} / \mathrm{L})$, likely due to decreased intake of breastmilk and physiological loss of extracellular fluid, which characterize the first few days of life $[14,15]$. Furthermore, there was no significant change in serum sodium levels possibly because the donor mean sodium level of $143 \mathrm{mEq} / \mathrm{L}$ was almost equal to that of the patient before EBT. These observations differ from those of earlier workers who have reported transient but significant hypernatremia after exchange by hypernatremic donor blood [16], but consistent with the findings of Patra K, et al. [9]. Clinical hyperkalemia resulting from RBC transfusions has been recognized as a transfusion complication for decades and the risk increases with the duration of blood storage and irradiation of donor blood. The rise in patient potassium after transfusion is usually transient due to the redistribution of the potassium load within the body $[10,16]$. In contrast to above discussion we observed a statistically significant fall in mean serum potassium during and in post exchange period, though within the normal physiological range. The fall in serum potassium persisted even at 12 hours post-exchange. The lower serum potassium levels may be because we mostly used fresh irradiated donor blood for exchange transfusion, which mitigated chances of significant hyperkalemia. Further the low serum potassium coincided with higher serum $\mathrm{pH}$ (alkalosis), which is known to cause shift of serum potassium into intracellular compartment. Relatively higher serum $\mathrm{pH}$ may be attributed to higher serum bicarbonate concentration in freshly CPDA treated blood. The concentration of serum bicarbonate in CPDA treated blood usually starts decreasing after 3 days of storage [17].

We observed a statistically significant decrease in serum calcium during transfusion, though within physiologically normal range. Such fall occurs due to calcium chelating properties of citrate which is present in high concentration in CPDA treated donor blood $[17,18]$. Singh $M$, et al. in their study on effect of exchange trans- fusion on bilirubin and calcium level in neonatal hyperbilirubinemia observed a transient rise in serum calcium in post-exchange period which was attributed to routine intravenous administration of $10 \%$ calcium gluconate after each $100 \mathrm{ml}$ of blood exchange in order to counteract any fall in serum ionized calcium levels [18]. In our study we did not employ routine use of i.v. calcium gluconate during exchange transfusion. There was a significant rise in post exchange serum glucose, attributed to high dextrose content in the donor blood along with anticoagulants for the preservation [13]. Although normal mean blood sugar was observed at $12 \mathrm{hrs}$ post-exchange, one needs to be cautious as rebound hypoglycemia may occur during the initial hours. So, monitoring of blood glucose becomes mandatory and continuous glucose input may be needed for next few hours either by iv infusion or orally. Most current guidelines for exchange transfusion recommend donor blood which is as fresh as possible (preferably less than 5 days old) to avert any possible complications [19]. In our study we did not observe any physiologically significant change in biochemical milieu during and after exchange transfusion. The possible explanation is that we mostly employed fresh donor blood (mean age 2.24 days) for exchange transfusion.

\section{Conclusion}

The study demonstrated changes in serum glucose, potassium and calcium levels which were not clinically significant and resolved spontaneously within 12 hours. However, in contrast to the earlier reports of higher incidence of hyperkalemia during exchange transfusion, we observed a paradoxical fall in serum potassium during and after transfusion, although within normal range. The lower serum potassium levels were attributed to use of mostly fresh irradiated blood for transfusion and possible intracellular shift due to concomitant relative metabolic alkalosis due to CPDA treatment of donor blood. Further, we reported that routine intravenous calcium gluconate is not needed if fresh blood is employed for exchange transfusion.

\section{Authors' Contribution}

Dr. Syed Wajid and Dr. Bashir Ahmad Charoo conceptualized and designed the study, drafted the initial manuscript, coordinated and supervised data collection and approved the final manuscript as submitted. $\mathrm{Mr}$ Mohd Ibrahim and Dr. Mohd Rafiq carried out the initial analyses, reviewed and revised the manuscript, and approved the final manuscript as submitted.

Dr. Mudasir Nazir and Dr. Roumissa Lone designed the data collection instruments, and coordinated and supervised data collection, critically reviewed the manuscript, and approved the final manuscript as submitted.

\section{Financial Disclosure}

The authors have no financial relationships relevant to this article to disclose. 


\section{Conflict of Interest}

The authors have no conflicts of interest relevant to this article to disclose.

\section{References}

1. Ip S, Chung M, Kulig J, O'Brien R, Sege R, et al. (2004) An evidence-based review of important issues concerning neonatal hyperbilirubinemia. Pediatrics 114: e130-e153.

2. NNPD network (2005) National neonatal perinatal database 2002-03. Indian Council of Medical Research, New Delhi, 24-37.

3. Muchowski KE (2014) Evaluation and treatment of neonatal hyperbilirubinemia. Am Fam Physician 89: 873-878.

4. Bhutani VK, Stark AR, Lazzeroni LC, Poland R, Gourley GR, et al. (2013) Pre-discharge screening for severe neonatal hyperbilirubinemia identifies infants who need phototherapy. J Pediatr 162: 477-482.

5. Sgro M, Campbell DM, Kandasamy S, Shah V (2012) Incidence of chronic bilirubin encephalopathy in Canada, 20072008. Pediatrics 130: e886-e890.

6. Gamaleldin R, Iskander I, Seoud I, Aboraya H, Aravkin A, et al. (2011) Risk factors for neurotoxicity in newborns with severe neonatal hyperbilirubinemia. Pediatrics 128: e925-e931.

7. Newman TB, Kuzniewicz MW, Liljestrand P, Wi S, McCulloch C, et al. (2009) Numbers needed to treat with phototherapy according to American Academy of Pediatrics guidelines. Pediatrics 123: 1352-1359.

8. Chen WX, Wong VC, Wong KY (2006) Neurodevelopmental outcome of severe neonatal hemolytic hyperbilirubinemia. J Child Neurol 21: 474-479.
9. Patra K, Storfer-Isser A, Siner B, Moore J, Hack M (2004) Adverse events associated with neonatal exchange transfusion in the 1990s. J Pediatr 144: 626-631.

10. Vraets A, Lin Y, Callum JL (2011) Transfusion-associated hyperkalemia. Transfus Med Rev 25: 184-196.

11. Cloherty JP, Eichenwald EC, Stark AR (2012) Manual of neonatal care. $\left(7^{\text {th }}\right.$ edn), Lippincott Williams \& Wilkins Philadelphia, USA.

12. American Academy of Pediatrics Subcommittee on Hyperbilirubinemia (2004) Management of hyperbilirubinemia in the newborn infant 35 or more weeks of gestation. Pediatrics 114: 297.

13. Jackson JC (1997) Adverse events associated with exchange transfusion in healthy and ill newborns. Pediatrics 99: 7.

14. Tarcan A, Tiker F, Vatandas NS, Haberal A, Gurakan B (2005) Weight loss and hypernatremia in breastfed babies: Frequency in neonates with non-hemolytic jaundice. J Pediatr Child Heath 41: 484-487.

15. Chitty HE, Ziegler N, Savoia H, Doyle LW, Fox LM (2013) Neonatal exchange transfusions in the 21st century: A single hospital study. J Paediatr Child Health 49: 825-832.

16. Hess JR (2010) Red cell storage: When is better not good enough? J Proteomics 73: 368-373.

17. Hess JR (2010) Red cell changes during storage. Transfus Apher Sci 43: 51-59.

18. Singh M, Singh M, Tiwari S (2015) Effect of exchange transfusion in bilirubin and calcium level in neonatal hyperbilirubinemia. Int J Med Res Rev 3: 733-737.

19. Abdelghaffar S, Mansi Y, Ibrahim R, Mohamed D (2012) Red blood transfusion in preterm infants: Changes in glucose, electrolytes and acid base balance. Asian J Transfus Sci 6: 36-41. 